\title{
Linkage Knowledge Management and Data Mining in E-business: Case study
}

\author{
Ming-Chang Lee \\ Department of Information Management, Fooyin University, Taiwan, R. O. C. \\ Department of Business Administration, National Kaohsiung University of applied \\ Sciences, Taiwan
}

\begin{abstract}
E-business has changed the face of most business functions in competitive enterprises. E-business functions are enterprise resource planning (ERP) and related systems such as supply chain management (SCM) and customer relationship management (CRM), are incorporating decision support tools and technologies. Data mining has matured as a field of basic and applied research in e-business. Effective knowledge management (KM) enhances products, improves operational efficiency, speeds deployment, increases sales and profits, and creates customer satisfaction. The aim of this study is to make an association with e-business, $\mathrm{KM}$ and data mining. Therefore, firstly, it will brief review the existing on knowledge management, e-business, and data mining, decision support system. We then present on linkages or supplementary relationships between the knowledge management and e-business with data mining. Secondly, knowledge, knowledge management and knowledge process is defined, and point out the need for integration with e-business. Thirdly, it introduces data mining and examined data mining in data warehouse environment. Fourth, the e-business is defined. Using this definition, it can drive e-business application architecture and knowledge process frameworks with business process. Finally, Integrating Intelligent Decision Support System and knowledge management with data mining model is discussed. It presents the proposed KM architecture and discusses how decision support system and data mining can enhance KM. In this study some suggestions are made to get knowledge with data mining, which will help, for the improvement of e-business. Chinese Motor Corporation's knowledge and Sequent Computer's knowledge are discussed.
\end{abstract}

Keywords: E-business; knowledge management; data mining; decision support system

\section{Introduction}

E-business is defined as Internet-mediated integration of business, applications, and information systems (Kalakota and Robinson, 1999). E-business is considered as a new business model that emerging in the Web-driven environment and has descended across the corporate world. Joyce and Winch (2005) draws upon the emergent knowledge of e-business model together with traditional strategy theory to provide a simple integrating 
framework for the evaluation and assessment of business models for e-business. Timmers (1998) proposed a business mode, it elements of a business model are (1) the business architecture for product, service and information flows (2) description of potential benefits (3) description of the sources of revenues. Business model are defined as summary of the value creation logic of an organization or a business network including assumptions about its partners, competitors and customers. Wald and Stammers (2001) proposed a model for e-businesses based on the separation between standard processes and e-processes.

Business, when properly linked with knowledge process and aligned with an organization's culture, aids a firm's strategic growth. The implementation of their e-business application also can benefit from experience acquired from their knowledge management practices. For example, Plessis and Boon (2004) studied e-business in South Africa and found that knowledge management is a prerequisite for e-business and its increasing customer-centric focus and is an integral part of both customer relationship management and e-business. Bose and Sugumaran (2003) found a U.S. application of KM technology in customer relationship management, particularly for creating, structuring, disseminating, and applying knowledge. The development of e-business, focus knowledge organizations is needed to enhance customer relationship management, supply management, and product development (Fahey et al., 2001).

DSS is a computer-based system that aids the process of decision-making (Finlay, 1994). DSS are interactive computer-based systems that help decision makers utilize data and models to solve unstructured problems. DSS can also enhance the tacit to explicit knowledge conversion by eliciting one or more what-if cases (i. e., model instances) that the knowledge worker wants to explore. That is, as the knowledge worker changes one or more model coefficients or right hand side values to explore its effect on the modeled solution. That is, the knowledge worker is converting the tacit knowledge that can be shared with other workers and leveraged to enhance decision. DSSs which perform selected cognitive decision-making functions and are based on artificial intelligence or intelligent agent's technologies are called Intelligent Decision Support Systems (IDSS) (Gadomaski, et al., 2001). IDSS was applied to solve problems faced by rice framers desiring to achieve maximum yields in choosing the proper enterprise management strategies. IDSS is needed and is economically feasible for generic problems that require repetitive decisions. Dhar and Stein (2000) use term to characterize the degree of intelligence provided by a decision support tool. It describes intelligence density as representing the amount of useful decision support information that a decision maker gets from using the output from some analytic system for a certain amount of time (2000).

Data mining is a decision-making functions (decision support tool). Data mining (DM) has as its dominant goal, the generation of no-obvious yet useful information for decision makers from very large data warehouse (DW). DM is the technique by which relationship and patterns in data are identified in large database (Fayyadand and Uthurusamy, 1995). Data Warehouse, an integral part of the process, provides an infrastructure that enables businesses to extract, cleanse, and store vast amount of corporate data from operational systems for efficient and accurate responses to user queries. DW empowers the knowledge workers with information that allows them to make decisions based on a solid foundation of fact (Devlin, 1997). In DW environment, DM techniques can be used to discover untapped pattern of data that enable the creation of new information. DM and DW are potentially critical technologies to enable the knowledge creation and management process (Berson and 
Smit, 1997). The DW is to provide the decision-maker with an intelligent analysis platform that enhances all phase of the knowledge management process. DSS or IDSS and DM can be used to enhance knowledge management and its three associated processes: i.e., tacit to explicit knowledge conversion, explicit knowledge leveraging, and explicit knowledge conversion (Lau et al., 2004). . The purpose of this study is to proposed KM architecture and discusses how to working DSS and data mining can enhance KM.

A firm can integrate an ERP (e- business) system with an IDSS in integrate existing DSS that currently sit on top of a firms' ERP system across multiple firms. Dharand Stein (2000). describes six steps of processing to transform data into knowledge. Figure 1 is showed as a framework of e-business and IDSS. The integration of ERP and IDSS can extend to include the collaboration of multiple enterprises. Firms need to share information with their supplier-facing partners. Firm need to gather information from their customer-facing partners (i.e. retailers, customers). Firm need to increase intelligent density through the various IDSS tools and technologies integrated with their respective e-business system. In multi- enterprise collaboration, it develop relationship with its partners through systems such as CRM, SCM, Business-to-Business (B2B), data warehouse, firms are able to provide their decision makers with analytical capabilities (i. e. OLAP, Data Mining, MOLAP). From Figure 1, the integrated of e-business and IDSS included ERP system, Enterprise Application integration and IDSS system.

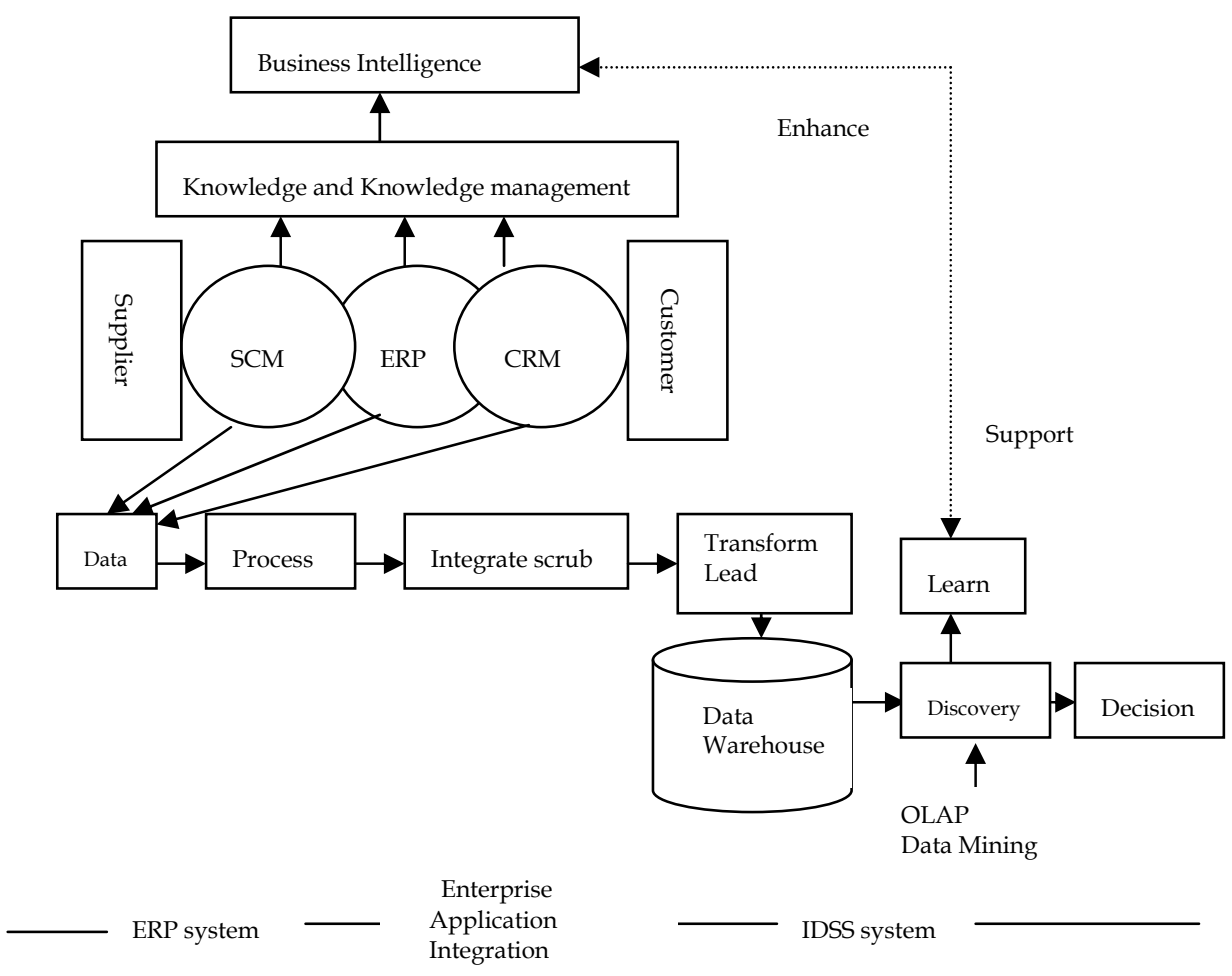

Fig. 1. Framework of e-business, knowledge management, data mining and IDSS, Source from: Lee and Cheng (2007) 


\section{Knowledge Management}

\subsection{Knowledge and Knowledge Management}

We define $\mathrm{KM}$ to be the process of selectively applying knowledge from previous experiences of decision making to current and future decision making activities with the manifestations of the same process only in different organizations. Knowledge management is the process established to capture and use knowledge in an organization for the purpose of improving organization performance (Marakas, 1999). Knowledge management is emerging as the new discipline that provides the mechanisms for systematically managing the knowledge that evolves with enterprise. Most large organizations have been experimenting with knowledge management with a view to improving profits, being competitively innovative, or simply to survive (Davenport and Prusak, 1998; Hendriks and Virens, 1999; Kalakota and Robinson, 1999; Loucopoulos and Kavakli, 1999). Knowledge management systems refer to a class of information systems applied to managing organization knowledge, which is an IT-based system developed to support the Organizational knowledge management behavior: acquisition, generation, codification, storage, transfer, retrieval (Alavi and Leidner, 2001). In face of the volatility and rate of change in business environment, globalization of marketing and labor pools, effective management of knowledge of organization is undoubtedly recognized as, perhaps, the most significant in determining organizational success, and has become an increasingly critical issue for technology implementation and management. In other words, KMS are meant to support knowledge processes. Knowledge management systems are the tools for managing knowledge, helping organizations in problem-solving activities and facilitating to making of decisions. Such systems have been used in the areas of medicine, engineering, product design, finance, construction and so on (Apostolou and Mentzas, 1999; Chau et al., 2002; Davenport and Prusak, 1998; Hendriks and Virens, 1999).

Knowledge assets are the knowledge of markets, products, technologies and organizations, that a business owns or needs to own and which enable its business process to generate profits, and value, etc. KM is not only managing these knowledge assets, but managing the processes that act upon the assets. These processes include: developing knowledge, preserving knowledge, using knowledge, and sharing knowledge. From an organizational point of view, Barclay and Murray (1997) consider knowledge management as a business activity with two primary aspects. (1) Treating the knowledge component of business activities as explicit concern of business reflected in strategy, policy, and practice at all levels of the organization. (2) Making a direct connection between an organization's intellectual assets - both explicit and tacit - and positive business results.

The key elements of knowledge management are collaboration, content management and information sharing (Duffy, 2001). Collaboration refers to colleagues exchanging ideas and generating new knowledge. Common terms used to describe collaboration include knowledge creation, generation, production, development, use and organizational learning (Duffy, 2001). Content management refers to the management of an organization's internal and external knowledge using information skills and information technology tools. Terms associated with content management include information classification, codification, storage and access, organization and coordination (Alavi and Leidner, 2001; Davenport and Prusak, 1998; Denning, 1999). Information sharing refers 
to ways and means to distribute information and encourage colleagues to share and reuse knowledge in the firm. These activities mat be described as knowledge distribution, transfer or sharing (Alavi and Leidner, 2001; Davenport and Prusak, 1998; Duffy, 1999). Nonaka and Takeuchi (1995) view implicit knowledge and explicit knowledge as complementary entities. There contend that there are four modes (Socialization, Externalization, Combination, and Internalization) in which organizational knowledge is created through the interaction and conversion between implicit and explicit knowledge. Figure 2 is denoted as conversion of tacit to explicit knowledge and voice versa (or a cyclical conversion of tacit to explicit knowledge).

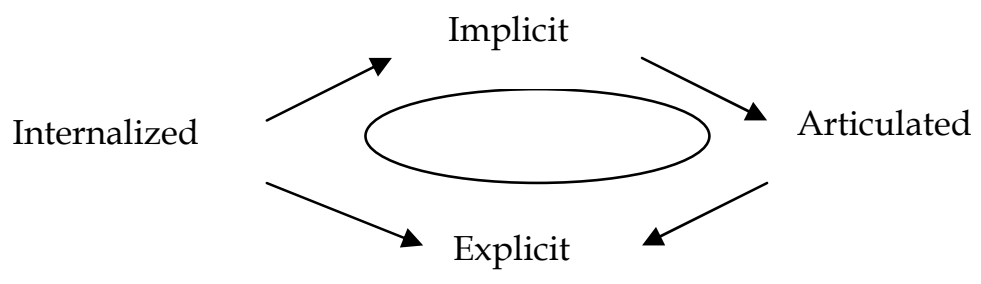

Fig. 2. A cyclical conversion of tacit to explicit knowledge

\subsection{Knowledge process}

Common knowledge management practices include: (1) Creating and improving explicit knowledge artifacts and repositories (developing better databases, representations, and visualizations, improving the real-time access to data, information, and knowledge; delivering the right knowledge to the right persons at the right time). (2) Capturing and structuring tacit knowledge as explicit knowledge (creating knowledge communities and networks with electronic tools to capture knowledge and convert tacit knowledge to explicit knowledge). (3) Improving knowledge creation and knowledge flows (developing and improving organizational learning mechanisms; facilitating innovation strategies and processes; facilitating and enhancing knowledge creating conversations/dialogues). (4) Enhancing knowledge management culture and infrastructure (improving participation, motivation, recognition, and rewards to promote knowledge sharing and idea generation; developing knowledge management enabling tools and technologies). (5) Managing knowledge as an asset (identifying, documenting, measuring and assessing intellectual assets; identifying, prioritizing, and evaluating knowledge development and knowledge management efforts; document and more effectively levering intellectual property). (6) Improving competitive intelligence and data mining strategies and technologies.

This process focuses on tacit to tacit knowledge linking. Tacit knowledge goes beyond the boundary and new knowledge is created by using the process of interactions, observing, discussing, analyzing, spending time together or living in same environment. The socialization is also known as converting new knowledge through shared experiences. Organizations gain new knowledge from outside its boundary also like interacting with customers, suppliers and stack holders. By internalization explicit knowledge is created using tacit knowledge and is shared across the organization. When this tacit knowledge is read or practiced by individuals then it broadens the learning spiral of knowledge creation. Organization tries to innovate or learn when this new knowledge is shared in 
socialization process. Organizations provide training programs for its employees at different stages of their working with the company. By reading these training manuals and documents employees internalize the tacit knowledge and try to create new knowledge after the internalization process. Therefore, integration organizational elements through a knowledge management system created organizational information technology infrastructure and organizational cluster (see Figure 3).

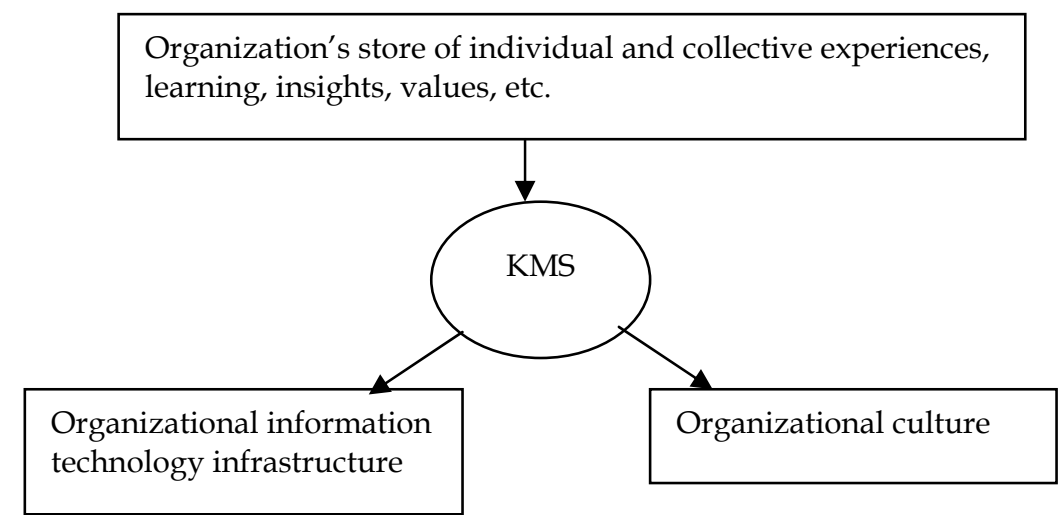

Fig. 3. Integration organizational elements through a knowledge management system

\subsection{SECI process and knowledge creation flow}

Nonaka (1994) proposes the SCEI model, which asserts that knowledge creation is a spiral process of interactions between explicit and tacit knowledge. Socialization is a process of creating tacit knowledge through share experience. Externalization is a process of conversion of tacit knowledge into explicit knowledge supported by metaphors and analogies. Combination involves the conversion of explicit knowledge into more complex sets of explicit knowledge by combining different bodies of explicit knowledge held by individuals through communication and diffusion processes and the systemization of knowledge. Internalization is the conversion of explicit knowledge into tacit knowledge. The four models of knowledge creation allow us to conceptualize the actualization of knowledge with social institutions through a series of self-transcendental processes. An organization itself will not be capable of creating knowledge without individuals, but knowledge spiral will not occur if knowledge is not shared with others or does not spread out the organization. Thus, organizational knowledge creation can be viewed as an upward spiral process, starting at the individual level moving up to the collective (group) level, and then to the organization al level, sometimes reaching out to the inter-organizational level. Figure 4 illustrates the spiral SECI model across individual, group, organization, and inter-organization granularities.

The core behavioral assumption in the model is that knowledge creating companies continually encourage the flow of knowledge between individuals and staff groups to improve both tacit and explicit knowledge stocks. The critical knowledge management assumption of the SECI process is the knowledge is created and improved as it flows through different levels of the organization and between individuals and groups. Thus 
knowledge value is created through synergies between knowledge holders (both individual and group) within a supportive and developmental organization context. The core competencies of organization are linkage to explicit and tacit knowledge (see Figure 5). Figure 6 is denoted as the key elements of the SECI model.

Epistemological

dimension

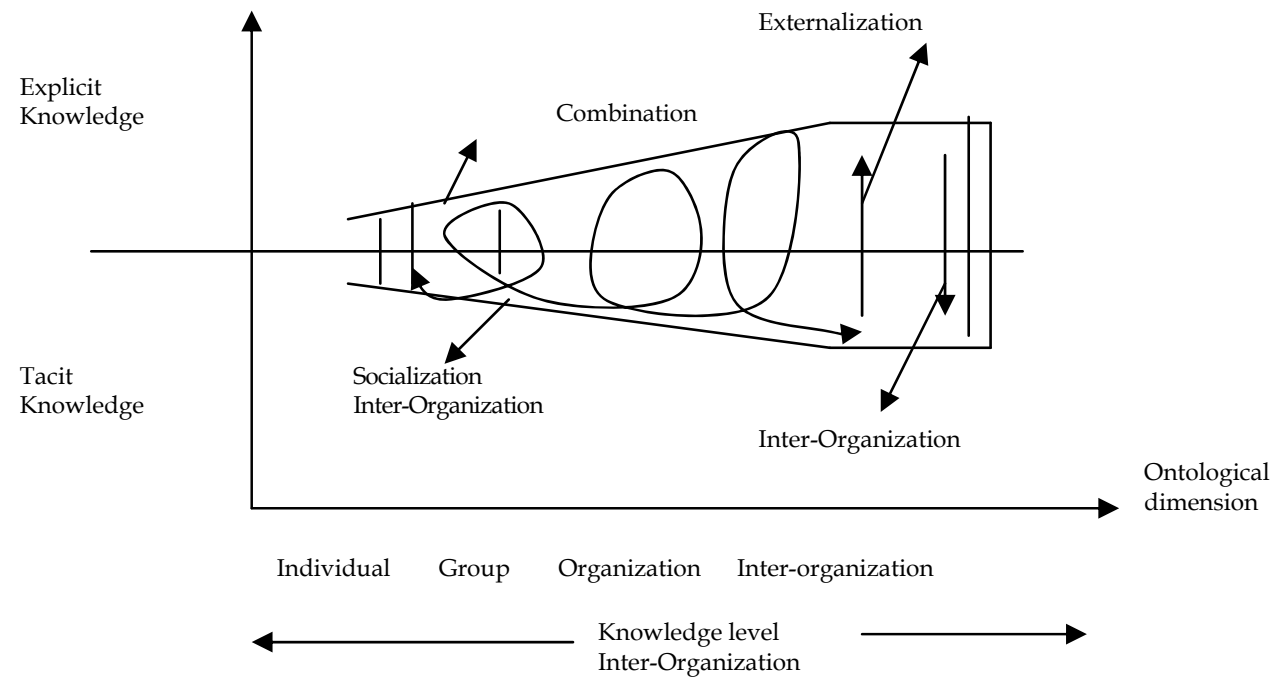

Fig. 4. Spiral of Organization Knowledge Creation (Nonaka, 1994)

Process of explication may generate

Explicit
Knowledge

Fig. 5. the core competency of the organization 


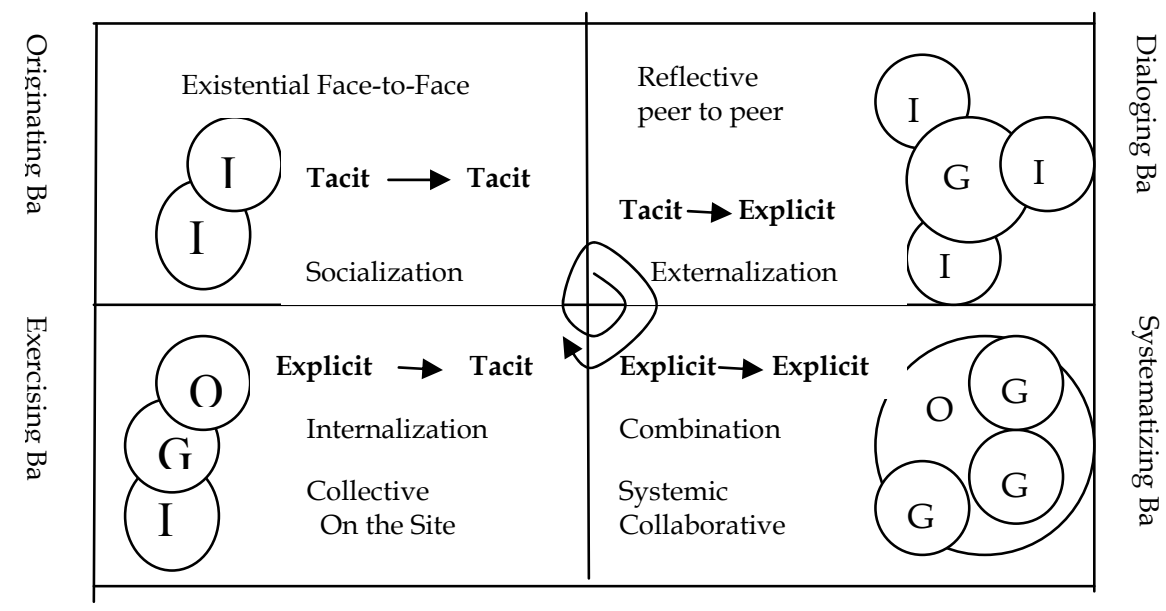

Fig. 6. The key elements of the SECI model (Nonaka, et al., 2000; Nonaka, et all., 2001)

In Figure 6, I, G, O symbols represent individuals, group and organization aggregates. Four different notions of $\mathrm{Ba}$ are defined in relation to each of the gour quadrants of the SECI model which make up the knowledge spiral. These are as follows:

1. The Originating Ba: a local where individuals can share feelings, emotions, experiences and perceptual models.

2. The Dialoguing Ba: a space where tacit knowledge is transferred and documented to explicit form. Two key methods factors are through dialogues and metaphor creation.

3. The Systematizing Ba: a vitual space, where information technology facilitates the recombination of existing explicit knowledge to form new explicit knowledge.

4. The Exercising Ba: a space where explicit knowledge is converted into tacit knowledge.

\section{Data mining methods}

Data mining is a process that uses statistical, mathematical, artificial intelligence, and machine learning techniques to extract and identify useful information and subsequent knowledge from large databases (Nemati and Barko, 2001). The various mechanism of this generation includes abstractions, aggregations, summarizations, and characterizations of data (Chau, et al., 2002). If you are a marketing manager for an auto manufacturer, this somewhat surprising pattern might be quite valuable. DM uses well-established statistical and machine learning techniques to build models that predict customer behavior. Today, technology automates the mining process, integrates it with commercial data warehouses, and presents it in a relevant way for business users.

Data mining includes tasks such as knowledge extraction, data archaeology, data exploration, data pattern processing, data dredging, and information harvesting. The following are the major characteristics and objectives of data mining:

. Data are often buried deep within very large databases, which sometimes contain data from several years. In many cases, the data are cleansed and consolidated in a data 
warehouse.

. The data mining environment is usually client/server architecture or a web-based architecture.

- Data mining tools are readily combined with spreadsheets and other software development tools. Thus, the mined data can be analyzed and processed quickly and easily.

. Striking it rich often involves finding an unexpected result and requires end users to think creatively.

. Because of the large amounts of data and massive search efforts, it is sometimes necessary to used parallel processing for data mining.

\subsection{Data mining in data warehouse environment}

The data warehouse is a valuable and easily available data source for data mining operations. Data extractions the data mining tools work on come from the data warehouse. Figure 7 illustrates how data mining fits in the data warehouse environment. Notice how the data warehouse environment supports data mining.

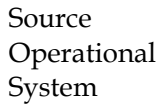

System

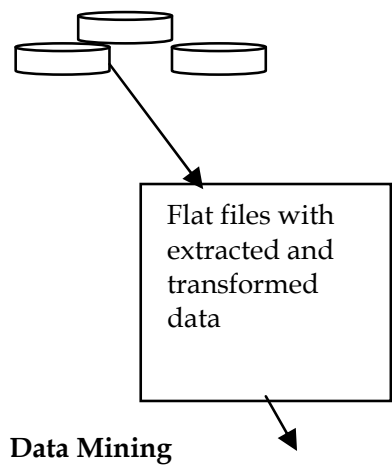

OLAP

System

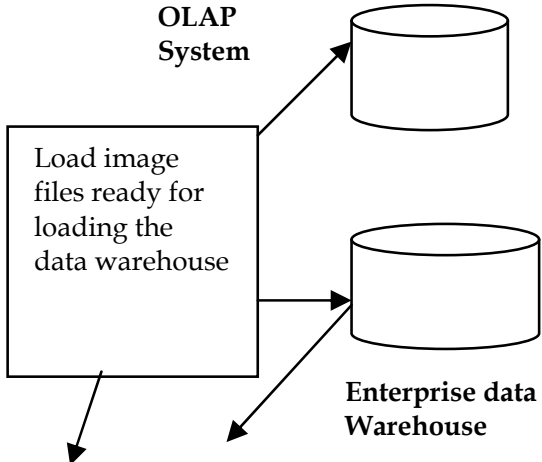

Data selected, extracted, transformed, and prepared for mining

Fig. 7. Data mining in data warehouse environment

\subsection{Decision support progress to data mining}

Business analytics (BA), DSS, and KM apparatus enable both active and passive delivery of information from large scale DW, providing enterprises and managers with timely answers to mission-critical questions. The objective of these apps is to turn the enormous amounts of available data into knowledge companies can used. The growth of this class of apps has been driven by the demand for more competitive business intelligence and increases in electronic data capture and storage. In addition, the emergence of the Internet 
and other communications technologies has enabled cost-effective access to and delivery of information to remote users throughout the world. Due to these factors, the overall for BA, KM, and DSS is projected to grow substantially.

Link all decision support systems, data mining delivers information. Please refer to Figure 8 showing the progression of decision support.

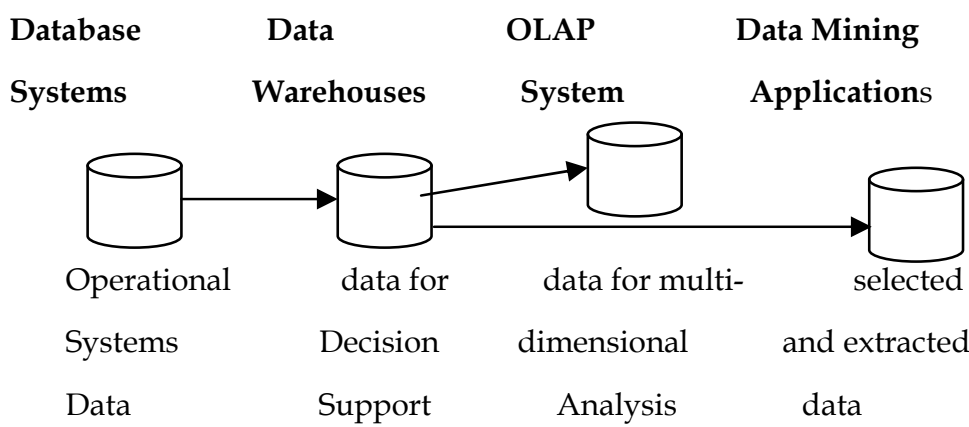

Fig. 8. Decision support progresses to data mining

Progressive organizations gather enterprise data from the source operational systems, move the data through a transformation and cleansing process, and store the data in data warehouse in a form suitable for multidimensional analysis.

\subsection{Integration of knowledge management and data warehouse}

\subsubsection{Data warehouse and Knowledge management}

Knowledge management system (KMS) is a systematic process for capturing, integrating, organizing, and communicating knowledge accumulated by employees. It is a vehicle to share corporate knowledge so that the employees may be more effective and be productive in their work. Knowledge management system must store all such knowledge in knowledge repository, sometimes called a knowledge warehouse. If a data warehouse contains structured information, a knowledge warehouse holds unstructured information. Therefore, a knowledge framework must have tools for searching and retrieving unstructured information. Figure 9 is integration of KM and data warehouse. 


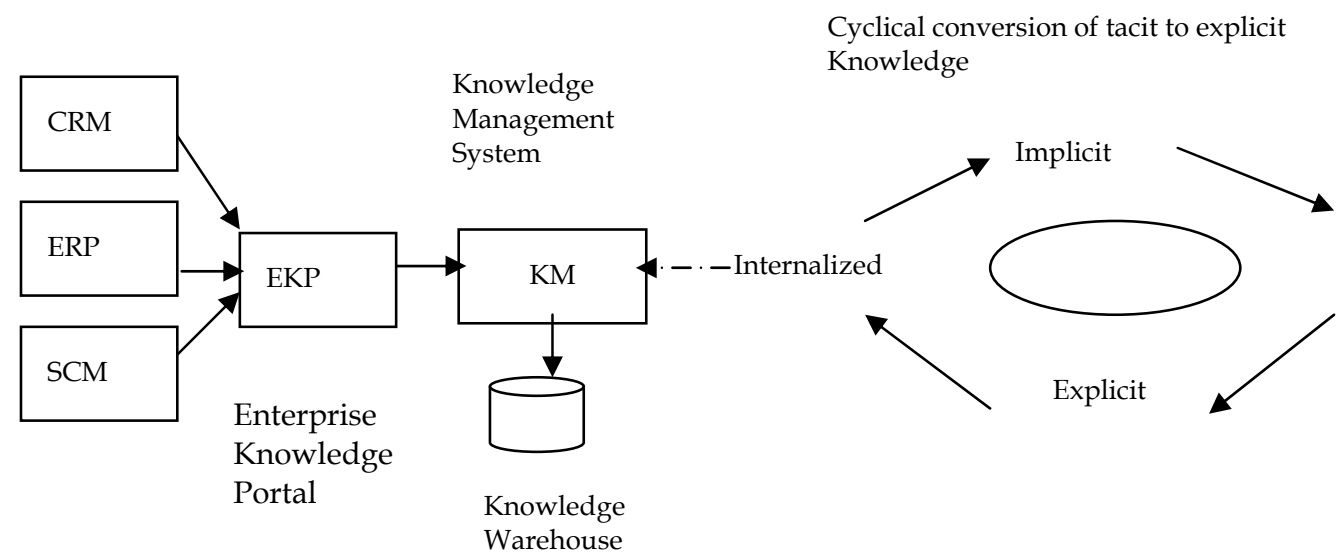

Fig. 9. Integration of $\mathrm{KM}$ and data warehouse

\subsubsection{Knowledge discovery in data warehouse}

Knowledge discovery Databases (KDD) in DW is a process used to search for and extract useful information from volumes of document and data. It include task such as knowledge extraction, data archaeology, data exploration, data pattern processing, data dredging and information harvesting. All these activities are conduct automatically and allow quick discovery, even by nonprogrammers. AI methods are useful data mining tools that include automated knowledge elicitation from other sources. Data mining tools find patterns in data and may even infer rules from them. Pattern and rules can be used to guide decision making and forecast the effects of decision. KDD can be used to identify the meaning of data or text, using knowledge management tools that scan documents and e-mail to build an expertise profile of a firm's employees.

Extending the role of data mining and knowledge discovery techniques for knowledge externalization, Bolloju et al. (1997) proposed a framework for integrating knowledge management into enterprise environment for next-generation decision support system. The knowledge track knowledge center offers integrated business-to-business functions and can scale from Dot-COM to large enterprise sitting on top, the way most intranet portals do. The knowledge center integrates with external data houses, including enterprise resource planning (ERP), online analytical process (OLAP), and customer relationship management (CRM) systems.

\subsubsection{Integrating DSS and Knowledge}

While DSS and knowledge management are independent activities in many organizations, they are interrelated in many others. Herschel and Jones (2005) discuss of knowledge management, business intelligence (BI) and their integration. Bolloju et al. (2002) proposed a framework for integrating decision support and knowledge management processes, using knowledge-discovery techniques. The decision maker is using applications fed by a data warehouse and data marts and is also using other sources of knowledge. The DSS information and the knowledge are integrated in a system, and the 
knowledge can stored in the model base. The framework is based on the relationship shown in Figure 10. Framework for Integrating DSS and KMS

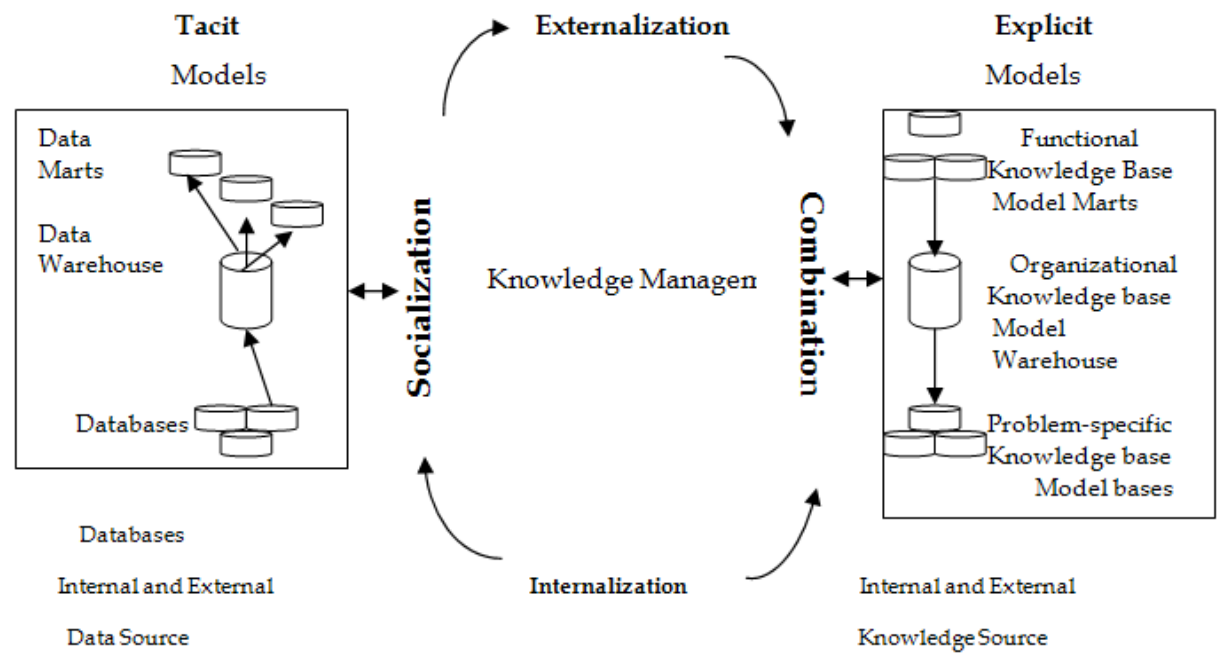

Fig. 10. Framework for Integrating DSS and KMS Source from :Bolloju and Turban (2002)

\section{E-business}

\subsection{E-business application architecture}

E-business is a broader term that encompasses electronically buying, selling, service customers, and interacting with business partner and intermediaries over the Internet. E-business describes a marketplace where businesses are using web-based and other network computing-based technologies to transform their internal business processes and their external business relationships. So e-business opportunities are simply a subset of the larger universe of opportunities that corporate investment boards consider everyday. Joyce and Winch (2005) draws upon the emergent knowledge of e-business model together with traditional strategy theory to provide a simple integrating framework for the evaluation and assessment of business models for e-business.

Enterprise resource planning (ERP) is a method of using computer technology to link various functions - such as accounting, inventory control, and human resources-across an entire company. ERP system supports most of the business system that maintains in a single database the data needed for a variety of business functions such as Manufacturing, supply chain management (SCM), financials, projects, human resources and customer relationship management (CRM). ERP systems developed by the Business Process Reengineering (BPR) vendors such that SAP was expected to provide lockstep regimented sharing the data across various business functions.

These systems were based on a top-down model of information strategy implementation and execution, and focused primarily on the coordination of companies' internal functions. The BPR vendors such that SAP are still evolving to develop better external information flow linkages in terms of CRM and SCM. The ERP functionality, with its internal focus, 
complements the external focus of CRM and SCM to provide a based for creating E-business applications.

Figure 11 shows how all the various application clusters are integrated to form the future model of the organization. The blueprint is useful because it assists managers in identifying near-term and long-term integration opportunities. Figure 11 also illustrates the underlying premise of e-business design. Companies run on interdependent application clusters. If one application cluster of the company does not function well, the entire customer value delivery system is affected

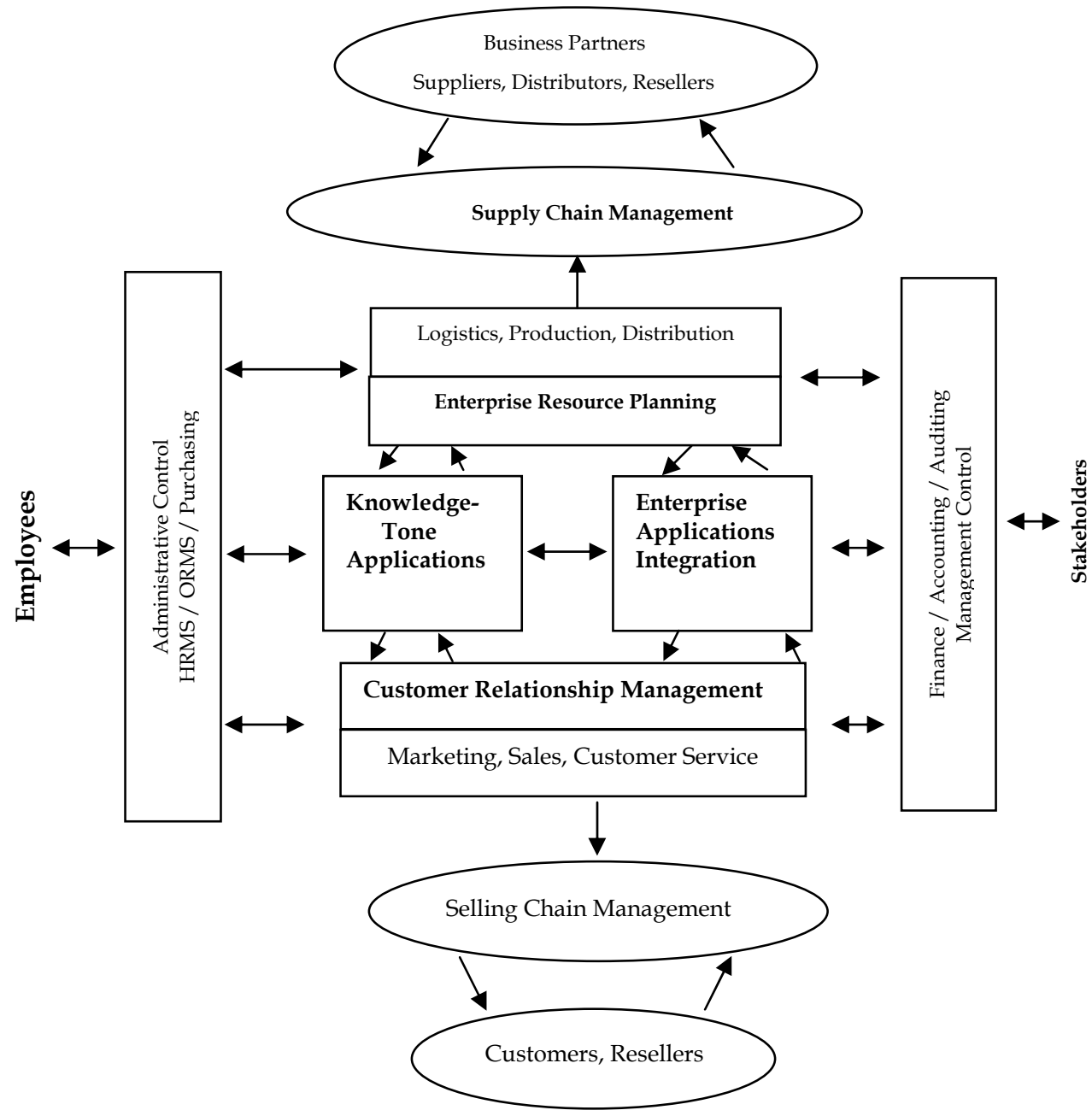

Fig. 11. E-business Application Architecture 


\subsection{Knowledge process framework with business}

A business process is defined as a set of logically related tasks performance to achieve a defined business outcome (Davenport and Robinson, 1999). The knowledge process through facilitating the transfer or creation of knowledge serves the business process. E-business is defined as Internet-mediated integration of business, applications, and information systems (Kalakota and Robinson, 1999). E-business is considered as a new business model that emerging in the Web-driven environment and has descended across the corporate world. Business, when properly linked with knowledge process and aligned with an organization's culture, aids a firm's strategic growth. The implementation of their e-business application also can benefit from experience acquired from their KM practices. For example, Plessis and Boon (2004) studied e-business in South Africa and found that knowledge management is a prerequisite foe e-business and its increasing customer-centric focus and is an integral part of both customer relationship management and e-business. Bose and Sugumaran (2003) found a U.S. application of KM technology in customer relationship management, particularly for creating, structuring, disseminating, and applying knowledge. The development of e-business, focus knowledge organizations is needed to enhance customer relationship management, supply management, and product development (Fahey, et al., 2001).

The Enterprise Resource Planning (ERP) systems developed by the Business Process Reengineering (BPR) vendors such that SAP was expected to provide lockstep regimented sharing the data across various business functions. These systems were based on a top-down model of information strategy implementation and execution, and focused primarily on the coordination of companies' internal functions. The BPR vendors such that SAP are still evolving to develop better external information flow linkages in terms of customer relationship management (CRM) and supply chain management (SCM). The ERP functionality, with its internal focus, complements the external focus of CRM and SCM to provide a based for creating E-business applications. The continue challenge remains in terms of ensuring the adaptability and flexibility of information interfaces and information flows. The more recent development of E-business architectures based on software components self-contained packages of functionality that can be snapped together to create complete business applications (Malhotra, 2000). Knowledge management and e-business would seem to supplement each other (Bose and Sugumaran, 2003). According the above argument, we have Framework of knowledge process with business process, and are shown as Figure 12. 
Knowledge sources and Create Knowledge

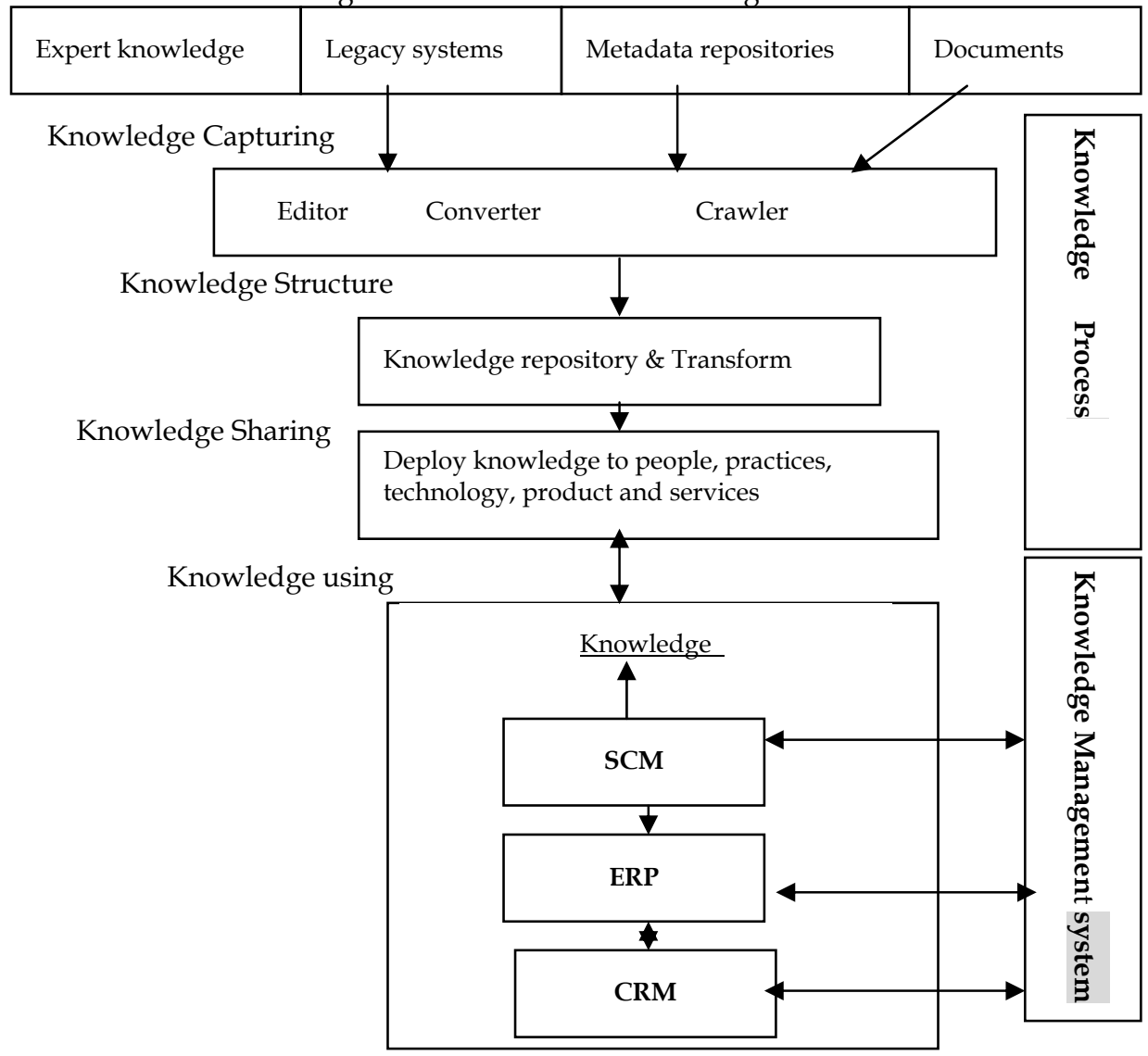

Fig. 12. knowledge Process frameworks with business process Source from: (Lee, 2008)

\subsection{Integration DSS and Knowledge management with data mining}

Knowledge management and e-business would seem to supplement each other (Bose and Sugumaran, 2003). The knowledge process through facilitating the transfer or creation of knowledge serves the business process. Business, when properly linked with knowledge process and aligned with an organization's culture, aids a firm's strategic growth. The implementation of their e-business application also can benefit from experience acquired from their KM practices. For example, Plessis and Boon [38] studied e-business in South Africa and found that knowledge management is a prerequisite foe e-business and its increasing customer-centric focus and is an integral part of both customer relationship management and e-business. The development of e-business, focus knowledge organizations is needed to enhance customer relationship management, supply management, and product development (Fahey, 2001). Knowledge management and 
e-business would seem to supplement each other (Bose and Sugumaran, 2003).

Enterprise develop relationship with their partners through system such as CRM, SCM, Business to Business (B2B) procurement, and Online Stores (Data Warehouse), firms are able to provide their decision makers with analytical capabilities. According to Power (2002), academics and practitioners have discussed building DSS in terms of four major components: (a) the user interface (b) the database, (c) the model and analytical tools, and (d) the IDSS architecture and network. Marakas (1999) proposes a generalized architecture made of five distinct parts: (a) the data management system, (b) the model management system, (c) the knowledge engine, (d) the user interface, and (e) the user(s). To collaborate at a multi-enterprise level, the firm connects with its partners through EAI technology, processes, and information with all their partners along their extended value chains. These partners in turn may also integrate their respective technologies, process, and information, thus creating a network like multi-enterprise collaborative structure. The implementation of multi-enterprise collaboration architecture is showed as Figure 13. In Figure 13, during the planning process, data and models are manipulated through DBMS, knowledge management system (KMS) and model base management systems (MBMS), respectively. Instructions for data modifications and model executions may come from the ES interface directly. The MBMS obtains the relevant input data for model executions from the MBMS and, in return, results generated from model executions are sent back to DBMS for storage. The data base also provides facts for ES as part of the Knowledge base. Using these facts together with the predefined rules, the interface ending on the ES performs model validations and planning evaluations, according to what a domain expert is support to do. In Data Warehouse, firms are able to provide their decision makers through with analytical capabilities and Data mining.

Many data mining practitioners seem to agree on a set of data mining functions that can be used in specific application areas. Various data mining techniques are applicable to each type of function. Table 1 is showed as the application areas, examples of mining functions, mining process, and mining techniques.

\begin{tabular}{|c|c|c|c|}
\hline $\begin{array}{l}\text { Application } \\
\text { area }\end{array}$ & Examples of Mining functions & $\begin{array}{l}\text { Mining } \\
\text { Process }\end{array}$ & $\begin{array}{c}\text { Mining } \\
\text { Techniques }\end{array}$ \\
\hline $\begin{array}{c}\text { Fraud } \\
\text { Detection }\end{array}$ & $\begin{array}{l}\text { Credit card frauds } \\
\text { Internal audits } \\
\text { Warehouse pilferage }\end{array}$ & Determination of variations & $\begin{array}{c}\text { Data Visualization } \\
\text { Memory-based } \\
\text { Reasoning }\end{array}$ \\
\hline $\begin{array}{l}\text { Risk } \\
\text { Assessment }\end{array}$ & $\begin{array}{l}\text { Credit card upgrade } \\
\text { Mortgage Loans } \\
\text { Customer Retention } \\
\text { Credit Ratings }\end{array}$ & Detection and analysis of link & $\begin{array}{l}\text { Decision Trees } \\
\text { Memory-based } \\
\text { Reasoning }\end{array}$ \\
\hline $\begin{array}{l}\text { Market } \\
\text { Analysis }\end{array}$ & $\begin{array}{l}\text { Market basket analysis } \\
\text { Target marketing } \\
\text { Cross selling } \\
\text { Customer Relationship } \\
\text { Marketing }\end{array}$ & $\begin{array}{c}\text { Predictive Modeling } \\
\text { Database segmentation }\end{array}$ & $\begin{array}{l}\text { Cluster Detection } \\
\text { Decision Trees } \\
\text { Link Analysis } \\
\text { Genetic Algorithm }\end{array}$ \\
\hline
\end{tabular}

Table 1. Data mining functions and application areas 


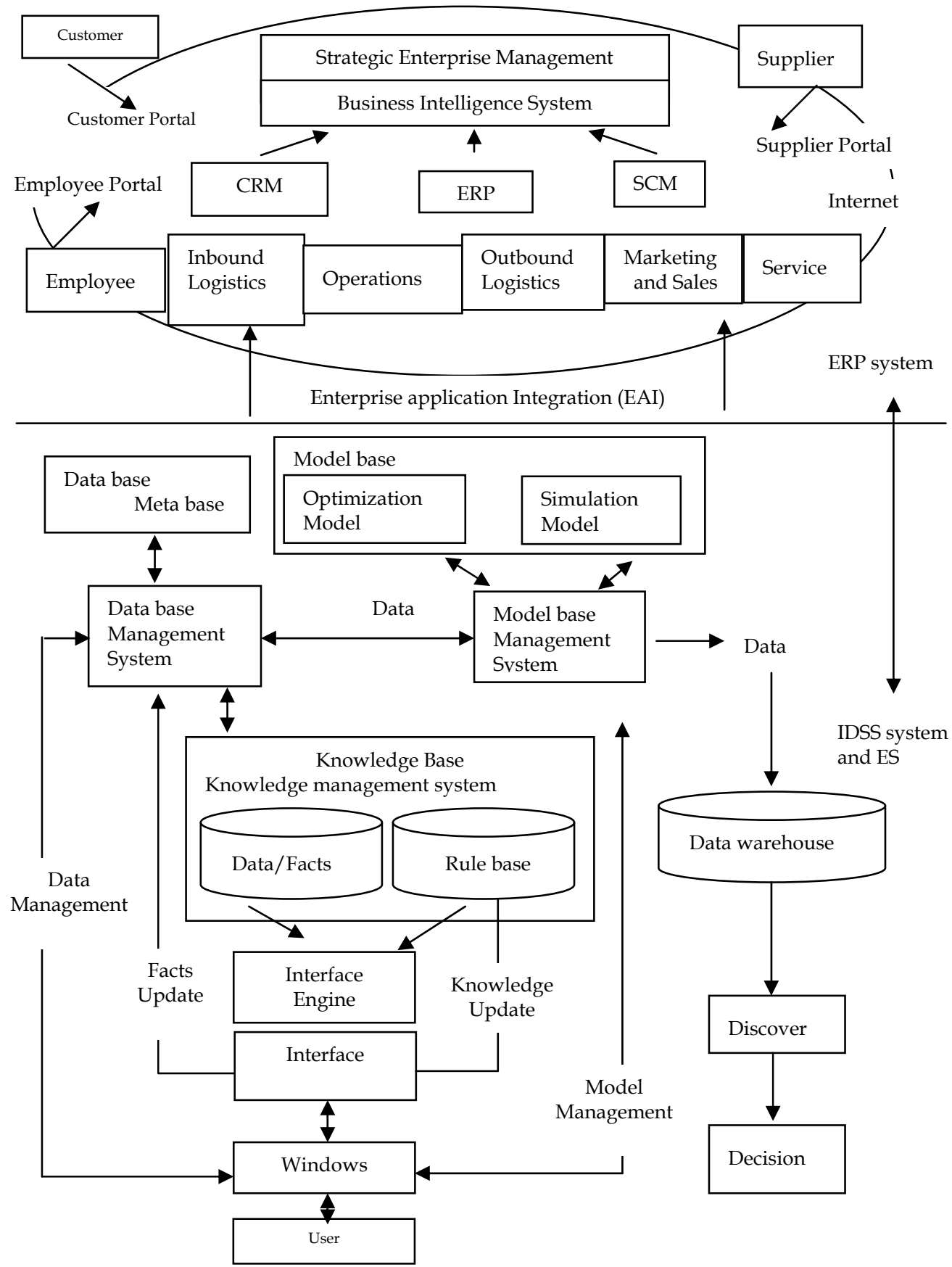

Fig. 13. The implementation of multi-enterprise collaboration architecture Source from: modified Cheung et al. (2005) 


\section{Case Study}

\subsection{Chinese Motor Corporation's knowledge}

\subsubsection{Company Overview}

CMC (Chinese Motor Corporation) was founded in June of 1969 and signed a technical collaboration with Mitsubishi Motors Corporation the following year. The Tang-Mei plant was completed at the end of 1973, establishing the manufacturing base for CMC's future growth. The company has been listed on Taiwan Stock Exchange (TSE) since March 1991.

Beginning with producing commercial vehicles, CMC is the leader of Taiwan's commercial vehicles manufactures. While the company's Yang-Mei plant produced less than 3000 vehicles per month through 1975, by the year 1983, total output had surpassed the 100, 000 unit mark. This was, in part, made possible by our most advanced painting facility in Taiwan. This was as well a prelude to the rapid growth that accompanied Taiwan's emergence as an industrial and economic power. Since 1987, CMC's revenues began an extended run of double-digit growth, gaining accolades as one of Taiwan's best-managed companies.

In 1993, the company garnered both ISO 9002 certification and the National Quality Award of Taiwan. In 1997, the company also obtained ISO 14001 environment Management certification. The company has invested in china's South East Motor Corporation (SEM) since 1995 our investment in China gives us access to one of the world's fastest-growing economies, while increased production capacity enables us to develop new models and penetrate foreign markets.

CMC is adept at taking advantage of market opportunities, and promoting fiscal transparency along with a merit-based personnel system that has molded its employees into a cohesive unit. Meanwhile, a cooperative, win-win purchasing system involving the enterprise and its suppliers has enhanced flexibility and improved quality. Thorough implementation of strategic policy has allowed the company to accurately access markets, and manufacture the right vehicle, at the right time

\subsubsection{Enterprise Operation}

CMC's business operations are guided by the principles expressed in the acronym HIT, which stands for Harmony, Innovation, and Top.

Harmony --True harmony allows the amicable resolution of problems and issues in a spirit of cooperation, creating a win-win situation. This is much like the interplay of instruments in any fine symphony orchestra. $\mathrm{CMC}^{\prime}$ s management strives to conduct its affairs to the benefit of all its constituencies: customers, employees, the government, society, shareowners, and suppliers. This creates a harmonious environment that offers mutual rewards.

Innovation --Innovation is the active process of invention, discovery, and improvement. It can also view as a continuous process of renewal providing a vision and wisdom that transcends transient condition. CMC is forever striving to enhance its existing competitive advantage through conceptual innovation in its product, technology, manufacturing process, management, and services.

Top-- Top is the litmus test for quality, much like the athlete who sets his sights on the ultimate goal. CMC expects Top performance in all phases of enterprise operations, 
strategic planning implementation, and long-term vision. Overall, the top concept benefits Taiwan's whole society.

Under enterprise operation, CMC build the knowledge management objective and organization. The strategic of building knowledge management are: higher-level manager support, plastic a sharing business culture, to plant one's feet on solid ground, to praise knowledge management contribution and application, to establish a platform of knowledge management.

E-Business model design and implementation in Supply-Chain Management based on DySco Framework. It has five stages: data-base, virtual communities, training center, intellectual capital and systematical knowledge. In data-base, it contains product knowledge, manufacturing knowledge, R \& D knowledge, and management knowledge and sale management. CMC knowledge management flow and structure are shown on figure 14 .

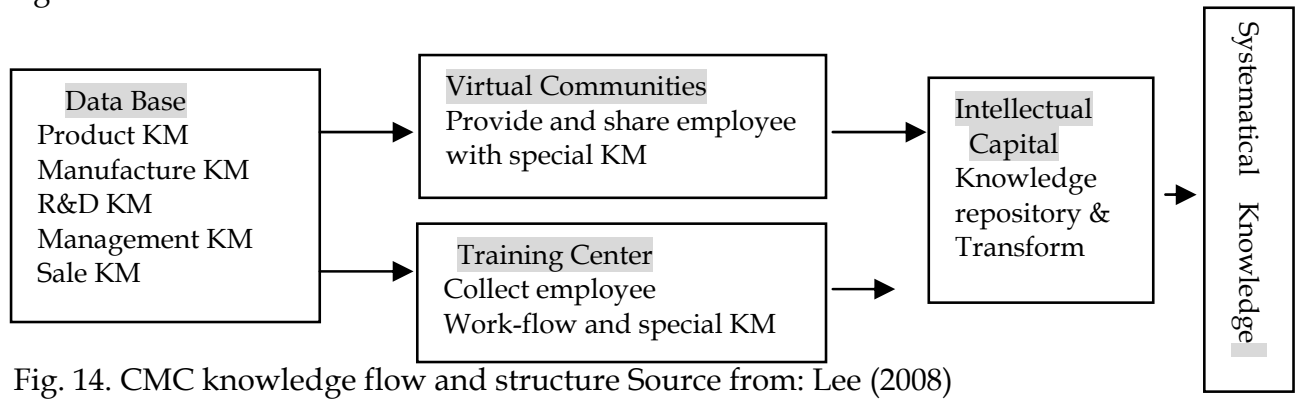

The China Motor Training Center is a professional training center. It has top quality space layout and all-inclusive design. It can be used for educational training, conferences, seminars, audio video reports, and product exhibition. CMC center is contains the following five features:

Convenient Location -- The China Motor Training Center is located next to the You Shi exit on the Zhong Shan Expressway. It is only a ten-minute drive from the Pu Shin Train Station and the Yang Mei Train Station. The location and transportation are convenient.

Complete Function -- A unique space designed specifically for training and conferences. A learning environment is in place with facilities that serve every function including quiet, interruption free classrooms, dining rooms, guest rooms, and recreation facilities.

Professional Facility -- Advanced audio/video equipment and teaching aids assure a high quality of learning and conferences. Guest rooms are decorated elegantly and warmly and are furnished in wood.

Training Consultation--Professional educators and trainers provide consultation on course teaching, training program design, instructor engagement, and location arrangement.

Total Service -- Complete coordination with businesses for various customs ordered accessories for special events, such as billboard advertisement placement, banners, flowers, etc. Provide free service for event decoration, and there is professional staff to provide 


\subsubsection{CMC business process and profit}

\section{(1) Division Profile}

Setting up a joint venture in Mainland China, known as South East Auto Industry LTD, which is one of the fast-growing auto-manufacturer in Mainland China. The capacity by two shifts is 160,000 units in 2004, and projected to expand up to 300,000 units in next stage. It participates in Mitsubishi's component complementary system. In the Mitsubishi Asian Car-Freeca (KZ) project, CMC is supplying $25 \%$ and $98 \%$ of parts to Mitsubishi's affiliate in the Philippines and Vietnam.

\section{(2) One-Stop-Shopping purchasing center of auto-parts}

CMC provides all kinds of exterior/interior and electrical parts, which can be easily applied to your vehicle to enhance your competitiveness in your local market. Being familiar with all parts suppliers in every category, total about 115 QS-9000-certificated suppliers in our parts supplying system, CMC is able to easily search for the right manufacturers that make products according to your drawings and engineering specifications. With our strong engineer teams in products-development division and quality-assurance division, CMC and its suppliers can work together for your products, especially in system integration, to provide a quick-responses and in-time delivery service. Now, we have been supplying our parts to United State, Southeast Asia, Japan and India. As a result, CMC is the best choice of regional agent for OEM/ODM parts in your out-sourcing program. Please check the below parts category, and find out what you need.

\subsubsection{CMC implements steps for driving knowledge management}

$\mathrm{CMC}$ is the leader of Taiwan commercial vehicles manufacturers. On driving e-business and knowledge management, $\mathrm{CMC}$ is a benchmark of learning in Taiwan companies. CMC implements steps for driving knowledge management are:

1. Communication and common view

Owing to the change of enterprise environment, $\mathrm{CMC}$ has more and more clear and definite knowledge requirement. For example, $\mathrm{CMC}^{\prime} \mathrm{s}$ technical department has straight knowledge requirement. It thinks to keep a successful experiment and technology. Therefore, CMC studies the possibility of entering knowledge management. In 2000 the former year, CMC the Internet part went deep into studying and a common view. The latter year, $\mathrm{CMC}$ investigated and visited some knowledge management successful companies. Knowledge management is long-term driving work; CMC stipulates and develops a knowledge view. IT becomes "big Chinese nation knowledge style enterprise benchmark". This benchmark is a guideline for employee communication and motion knowledge. CMC has four strategies: developing core knowledge, building knowledge platform, making sharing culture, and creating community network. It creates CMC knowledge development system, so CMC has changed from traditional business knowledge system.

2. Interior popularization

Three steps on $\mathrm{CMC}^{\prime}$ s knowledge interior popularization are: guide period, horizontal popularize, and basic level popularize. There are 42 discussion platforms in group discuss area. In improved area, there are 2700 articles of "knowledge" which employees afford.

3. Select suitable software technical company

Eland technical company (Taiwan) provided mellow knowledge management system. It 
provided Java solution, Web solution and good platform equipment. The product of Eland technical company for example, Work-flow can easily integrate other company.

\subsection{Sequent Computer's Knowledge}

\subsubsection{Background}

Sequent Computers is a virtual "David-holding-a-slingshot" unlike its major competitors HP, IBM, DEC and Sun Microsystems in the UNIX systems industry. Based in Beaverton, Oregon, it employs only 2,700 in 53 field locations in the US, Europe and Asia. As small as the company is, it is valued for providing multi-million dollar solutions to many industries. As such, the expertise of employees has become critical to its success.

Aware that customers value its knowledgeable sales force, Sequent began to manage knowledge like an asset in 1993 . It began by analyzing its business model by identifying and targeting its knowledge-sensitive points where improvement will yield the best results. The analysis revealed that the company would do best by focusing on its direct sales channel that is in close contact to its customers. The goal then was to make knowledge available to everyone so that each front-line employee in direct contact with the customers would be able to respond to them with the collective intelligence of the organization.

\subsubsection{The Sequent Corporate Electronic Library (SCEL)}

Sequent started KM by building the necessary technology infrastructure. SCEL or Sequent Corporate Electronic Library, an intranet site that contains corporate and individual knowledge domains focused on market and sales support to help employees do their jobs better.

IT and KM are two separate functions critical to SCEL. IT provides the technology, and human and financial resources to support KM programs. $\mathrm{KM}$ is responsible for the company's patent portfolio and the corporate library. A cross-functional SCEL team consists of librarians, a Web master, programmers, a SCEL architect, a SCEL evangelist, and other members linked to other parts of the organization.

SCEL includes a combination of database management systems, full text retrieval engines, file system storage, and complex structure of programs, all of which are integrated to Sequin's worldwide internal Web and accessible to all employees through Web browsers. SCEL works on a publisher/consumer relationship. Every employee is a publisher/consumer if they use SCEL. Publishers put knowledge into the system and consumers use that knowledge. Applying a laissez faire capitalist approach to knowledge, content is not controlled centrally. However, the influx of useful information as determined by the users is regulated by the SCEL team. User feedback is encouraged within the system. Outstanding presentations, strategy and script for sales calls and design documents are readily available. SCEL's other features are metadata capture, hyper-mail and a soon-to-be-developed partner library.

Sequent fosters a laissez-faire KM philosophy - the company's approach to practice and content is decidedly hands-off. Knowledge that comes to the system is not dictated by management but controlled by its direct users - whether information is helpful and meets their knowledge quality standards. 


\subsubsection{Results}

The KM efforts of Sequent have yielded good results. According to the company's KM leaders, SCEL has helped Sequent raise project average selling price, and reduce delivery and response time at all stages in the sales and post sales process. It has also increased the customer-specific and generic knowledge captured by its employees and customers. SCEL has focused the sales teams more effectively on proper targets and has made the assimilation process for new employees more efficient. Finally, the company has increased the customer-perceived value of its offerings, in hard (financial) and soft (loyalty) ways.

\subsubsection{Key Learning}

Based on Sequent's experience with SCEL, Swanson offers the following key leanings:

- Look for the business linkage. Think how knowledge can influence the world of its customers: for instance, sales folks are motivated by faster close cycles.

- Business means not just revenue generation, but also improving efficiency internally through best practice in operational processes.

- Technology is important. However, since more and more applications are being developed with the Web technology in mind, KM managers need not be preoccupied with the migration and development of new KM/ IT tools.

- Culture is very important. But do not wait for the culture to change to start implementing knowledge networks.

- Start small and don't worry about imperfections.

\section{SUMMARY AND CONCLUSION}

In this paper we have proposed a framework for integrating DSS and KMS as an extension to data warehouse model. The data warehouse and data mining will not only facilitate the capturing and coding of knowledge but will also enhance the retrieval and sharing of knowledge across the enterprise. The primary goal of the framework is to provide the decision marker with an intelligent analysis platform that enhances all phases of knowledge. In order to accomplish these goals, the DW used to search for and extract useful information from volumes of document and data. DSS can enhance the tacit to explicit knowledge conversion through the specification models. Specifically, in the model building process the knowledge worker is asked to explicitly specify the goal or objective of the model, the decision variables, and perhaps the relative importance of the decision variables. The knowledge warehouse will include a feedback loop to enhance its own knowledge base with the passage of time, as the tested and approved of knowledge analysis is fed back into the knowledge warehouse as additional source of knowledge.

A case study of China Motor Corporation is showing the process of knowledge used on e-business. It introduces CMC Enterprise Operation, CMC knowledge flow and structure, $\mathrm{CMC}$ implements steps for driving knowledge management, and CMC business process and profit. It is a guideline for enterprise entering knowledge process. This is an important issue as the system of future, including knowledge systems are designed to work together with applications that are developed on various platforms.

A case study of Sequent Computer is started KM by building the necessary technology infrastructure. SCEL or Sequent Corporate Electronic Library, an intranet site that 
contains corporate and individual knowledge domains focused on market and sales support to help employees do their jobs better.

\section{References}

Alavi, M. and Leidner, D. R. (2001), 'Review: Knowledge Management and Knowledge Management Systems: Conceptual Foundations and Research Issues', MIS Quarterly, Vol. 25, No. 1, pp. 107-136

Apostolou , D. and Mentzas, G., "Managing Corporate Knowledge: Comparative Analysis of Experiences in Consulting Firms", Knowledge and Process Management, Vol. 6,3, 1999, pp. 129-138.

Barclay, R. O. and Murray, P. C., What is Knowledge Management, A Knowledge Praxis, USA,1997.

Berson, A. and Smith, S., Data Warehouse, Data Mining, and OLAP, New York, McGraw-Hill, 1997.

Bolloju , N. M. and Turban, E., “Integrating Knowledge Management into Enterprise Environments for Next Generation of Decision Support", Decision Support Systems, Vol. 13, . 2002.

Bose, R. and Sugumaran, V., "Application of knowledge management technology in customer relationship management", Knowledge and Process Management, Vol. 10, 1, pp. 3-17, 2003.

Carbone, P. L., "Expanding the meaning of and applications for data mining", IEEE int. Conf. on System Man and Cybernetics, pp. 1872-1873, 2000.

Chau, L. W., Chuntian, C. and Li, C. W., (2002), 'Knowledge management systems on flow and water quality modeling', Expert System with Application, Vol. 22, pp. 321-330.

Cheung, W., Leung, L. C., and Tam, P. C.F.,(2005), An intelligent decision support system for service network planning, Decision Support System, 39, pp. 415-428

Davenport, T. and Prusak, L., (2000), “Working Knowledge: how organizations manage what they know", Harvard Business School Press, Boston

Davenport, T. and Prusak, L., Working Knowledge: how organizations manage what they know, Harvard Business School Press, 1998.

Davenport, T. H. and Short, L. (1990), 'The new Industrial Engineering: Information Technology and Business Process Redesign, MIT Sloan Management Review, Vol. 41, No. 4, pp. 11-27Gao et al., 2002

Denning, S., "The knowledge Perspective: A New Strategic Vision", The Knowledge Advantage, pp.143-161, 1999.

Devlin, B., Data warehouse: From Architecture to implementation, Addison Wesley Longman, Inc., Menlo Park, CA, 1997.

Dhar, V. and Stein, R., (2000), Intelligent Decision Support Methods: The Science of Knowledge Work, Prentice Hall, Upper Saddle River, N J., U.S.A.

Duffy, J., Knowledge management finally becomes mainstream, Information Management Journal, Vol. 35, 4, pp. 62-65, 2001.

Fahey, L., Srivastava, R., Sharon, J. S., and Smith, D. E., (2001), Linkage e-business and operating process: The role of knowledge management, IBM Systems Journal, 40(4), pp.889-907. 
Fayyad, U. M. and Uthurusamy, R., "First International Conference on Knowledge Discovery and Data Mining", AAAI Press, 1995.

Finlay, P. N. Introduction decision support systems, Oxford, UK Cambridge, Mass., NCC Blackwell; Blackwell Publishers. 1994.

Gadomaski, A. M. et al., "An approach to the Intelligent Decision Advisor (IDA) for Emergency Managers", International Journal Risk Assessment and Management, Vol. 2, 32001.

Hendriks, P. and Virens, D. (1999),'Knowledge -based systems and knowledge management: Friends or Foes?, Information \& Management, Vol. 30, pp. 113-125

Herschel, R. T. and Jones, N. E., "Knowledge Management and Blithe Importance of Integration", Journal of Knowledge Management, Vol. 9, 4, 2005.

Holsapple,C. W. and Sena, M., "ERP plans and decision Support Benefits", Decision Support System, Vol. 38, 4, 2005.

Joyce, P. and Winch, G. W., An e-business design and evaluation framework based on entrepreneurial, technical and operational considerations, International Journal of electronic Business, Vol. 2, 2005, pp. 198-214.

Kalakota, R. and Robinson, M., (1999), 'e-business: Roadmap for success', Reading, MA: Addison Wesley.

Lau, H. C. W. , Choy, W.L., Law, P. K. H., Tsui, W. T. T., and Choy, L. C., "An intelligent Logistics Support System for Enhancing the Airfreight Forwarding Business", Expert Systems, Vol. 21, 5, 2004.

Loucopoulos, P. and Kavakli, V. (1999),'Enterprise Knowledge Management and Conceptual Modeling', Lecture Notes in Computer Science, Vol. 1565, pp. 123-143

M. C. Lee and T. Chang, Linkage knowledge management and innovation management in e-business, International Innovation and learning, 4(2), 2007, pp. 145-159.

M. C. Lee, and J. F., Cheng, Development multi-Enterprise Collaborative Enterprise intelligent decision support system, Journal of Convergence Information Technology, 2(2), 2007 pp. 2-6.

M. C., Lee, Linkage Knowledge process and Business Process: A case study in China Motor Corporation, 2008 International Conference on Convergence and Hybrid Information Technology, 2008, pp.407-412

Malhotra, Y., (2000), 'Knowledge Management for E-Business Performance: Advancing Information Strategy to "Internet Time"', Information Strategy, The Executive's Journal, Vol.16, No. 4, pp. 5-16.

Marakas, G. M. (1999). Decision support systems in the twenty-first century. Upper Saddle River, N.J., Prentice Hall.

Nemati, H. R. and Barko, K. W., "Issues in Organizational Data Mining: A Survey of Current Practices", Journal of Data Warehousing, Vol. 6, 2, 2001(winter).

Nonaka, I. and Takeuchi, H., "The knowledge-creating company", Oxford University Press, NY, 1955.

Nonaka, I., A dynamic theory theory of organizational knowledge creation, Organization Sciences, 5(1), pp. 14-37, 1994. 
Nonaka, I., Toyama, R. and Konno, N.,SECI, Ba and Leadership: a Unified Model of Dynamic Knowledge Creation, Managing Industrial Knowledge: Creation, Transfer and Utilization, Sage, London, 2001, pp. 1-43.

Nonaka, T., Toyama, R. and Konno, N., (2000), 'SECI, and leadership: a. unified model of dynamic knowledge creation', Long Range Planning, Vol.33, No. 1, pp. 5-34

Plessis, M. and Boon, J. A., (2004),'Knowledge management in e-business and customer relationship management: South Africa case study finding,' International Journal of Information Management, 24 (10), pp. 73-85

Power, D. J. (2002). Decision support systems: concepts and resources for managers. Westport, Conn., Quorum Books.

Timmers, P., "Business models for Electronic Markets", EM-Electronic Markets Vol. 8, 2, pp. 3-8, 1998).

Tiwana, A. and Ramesh, B. (2001),'A design knowledge management system to support collaborative information product evolution', Decision Support Systems, Vol. 31, pp. 241-262

Wald, E. and Stammers, E., “Out of the alligator pool: a service-oriented approach to development", EAI Journal, March, pp. 26-30, 2001 


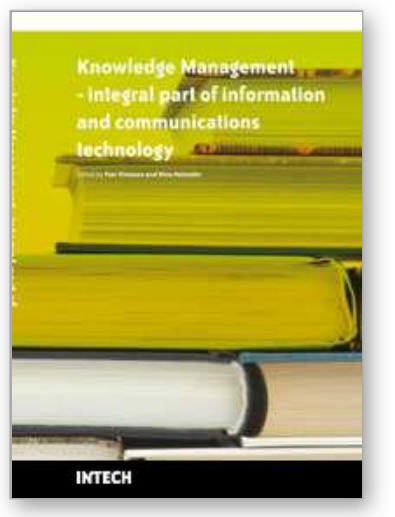

\author{
Knowledge Management \\ Edited by Pasi Virtanen and Nina Helander
}

ISBN 978-953-7619-94-7

Hard cover, 272 pages

Publisher InTech

Published online 01, March, 2010

Published in print edition March, 2010

This book is a compilation of writings handpicked in esteemed scientific conferences that present the variety of ways to approach this multifaceted phenomenon. In this book, knowledge management is seen as an integral part of information and communications technology (ICT). The topic is first approached from the more general perspective, starting with discussing knowledge management's role as a medium towards increasing productivity in organizations. In the starting chapters of the book, the duality between technology and humans is also taken into account. In the following chapters, one may see the essence and multifaceted nature of knowledge management through branch-specific observations and studies. Towards the end of the book the ontological side of knowledge management is illuminated. The book ends with two special applications of knowledge management.

\title{
How to reference
}

In order to correctly reference this scholarly work, feel free to copy and paste the following:

Ming-Chang Lee (2010). Linkage Knowledge Management and Data Mining in E-business: Case study, Knowledge Management, Pasi Virtanen and Nina Helander (Ed.), ISBN: 978-953-7619-94-7, InTech, Available from: http://www.intechopen.com/books/knowledge-management/linkage-knowledge-management-and-datamining-in-e-business-case-study

\section{INTECH}

open science | open minds

\author{
InTech Europe \\ University Campus STeP Ri \\ Slavka Krautzeka 83/A \\ 51000 Rijeka, Croatia \\ Phone: +385 (51) 770447 \\ Fax: +385 (51) 686166 \\ www.intechopen.com
}

\author{
InTech China \\ Unit 405, Office Block, Hotel Equatorial Shanghai \\ No.65, Yan An Road (West), Shanghai, 200040, China \\ 中国上海市延安西路65号上海国际贵都大饭店办公楼 405 单元 \\ Phone: +86-21-62489820 \\ Fax: +86-21-62489821
}


(C) 2010 The Author(s). Licensee IntechOpen. This chapter is distributed under the terms of the Creative Commons Attribution-NonCommercialShareAlike-3.0 License, which permits use, distribution and reproduction for non-commercial purposes, provided the original is properly cited and derivative works building on this content are distributed under the same license. 